\section{Urintest beeinflusst Trefferquote bei Zystoskopie}

\begin{abstract}
Bei Blasenkarzinom-Patienten ist die zystoskopische Untersuchung Standard in der Nachsorge. Wie stark ein zuvor erhobener Urintest die Effektivität der Zystoskopie mitbestimmt, wurde in einer prospektiven Studie untersucht.
\end{abstract}

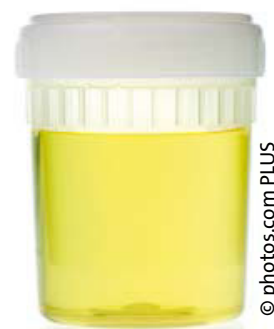

Rezidive in 131 Zystoskopien (32\%), wenn ihnen zuvor das Testergebnis mitgeteilt worden war, ohne diese Information nur sechs Rezidive bei 120 Zystoskopien $(5 \%, \mathrm{p}<0,001)$. Bei negativem Urintest zeigte sich kein signifikanter Unterschied bei den zystoskopisch diagnostizierten Rezidiven ( 7 vs. $6 \%, \mathrm{p}=0,45$ ).

Fazit: Diese Studie zeigt deutlich, dass die Exaktheit einer Zystoskopie keine feste Größe ist, sondern durch andere Testergebnisse signifikant beeinflusst wird. Bei positiven Urintests entdecken Urologen mit dem Endoskop signifikant mehr Rezidive.

af Gruppen zugeteilt. Im Interventionsarm mit 226 Patienten erfolgte in dreimonatigen Abständen ein Urintest auf das Vorliegen eines Blasenkarzinoms (Mikrosatelliten-DNA-Analyse). Bei positivem Befund sowie nach drei, zwölf und 24 Monaten wurde eine Zystoskopie durch- geführt. Der Urologe war dabei jeweils über das Testergebnis informiert. In der Kontrollgruppe mit 222 Patienten erfolgte alle drei Monate eine Zystoskopie, ohne dass der Urologe die Ergebnisse erfuhr.

Nach median 34 Monaten waren in der Interventionsgruppe 218 (bei 15\% der Zystoskopien) Rezidive entdeckt worden, in der Kontrollgruppe waren es mit 163 (10\% der Zystoskopien) signifikant weniger. Bei Patienten mit positivem Urintest diagnostizierten die Urologen 42

\section{Prostatakarzinom: fettarme Diät als Therapie?}

\section{Zu fettreiche Ernährung steht im Verdacht, Serumhormonen und} Wachstumsfaktoren zu beeinflussen und so für ein Prostatakarzinom zu prädisponieren. In der vorliegenden Studie untersuchten die Autoren den Effekt einer fettarmen Diät auf Serumfaktoren und deren Einfluss auf die Proliferation einer hormonsensitiven Prostatakarzinom-Zelllinie.

$\mathrm{Fs}_{\mathrm{s}}$ ühere Fall-Kontroll- und KohortenStudien fanden einen positiven $\mathrm{Zu}$ sammenhang zwischen Prostatakrebsrisiko und über die Mahlzeiten aufgenommener Gesamtfett-Menge. Omega3-Fettsäuren aus Fischkost sollen hingegen protektiv wirken. Welche Mechanismen dafür verantwortlich sind, ist noch weitgehend ungeklärt. Auch Sojaprotein wirkte in experimentellen Studien wachstumshemmend auf Prostatakarzinomzellen.

Die Autoren führten eine randomisierte interventionelle Studie mit 18 Männern durch, die neu an einem Prostatakarzinom erkrankt waren. Sie erhielten entweder eine vierwöchige fettarme Diät $(15 \% \mathrm{kcal})$ mit ballaststoffreichen Nahrungsmitteln und Supplementierung mit Sojaprotein oder die typische westliche Diät mit $40 \% \mathrm{kcal}$ Fettanteil. Vor und nach der Intervention bestimmten sie im Serum den Spiegel an Hormonen und Wachstumsfaktoren.
Kultivierte LNCaP-Prostatakarzinomzellen wurden mit den Seren beider Probandengruppen behandelt. Serum aus der Gruppe mit Niedrig-Fett-Diät wirkte signifikant hemmender auf das Zellwachstum als die Probe von Patienten mit „Western-Diät“. Allerdings waren keine Unterschiede in den Serumspiegeln von PSA, Geschlechtshormonen, Insulin, IGF I und II, IGFBP, Lipiden und Fettsäuren zu erkennen. In der Gruppe mit

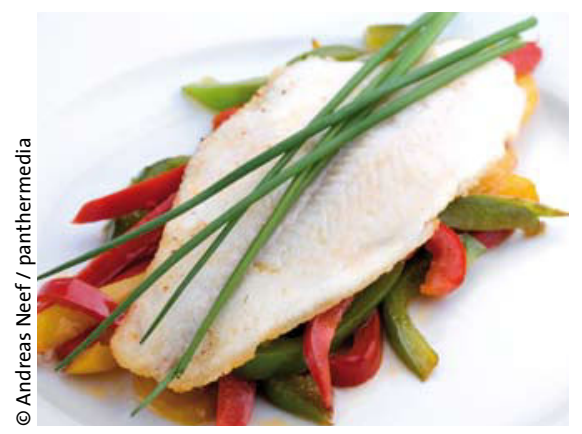

fettarmer Diät waren Serum-Triglyzeride und Linolsäure-Werte erniedrigt. In einer Korrelationsanalyse war ein erniedrigter Anteil von Omega-6-Fettsäuren und ein erhöhter Spiegel an Omega-3-Fettsäuren für den wachstumshemmenden Effekt auf die LNCaP-Prostatakarzinomzellen verantwortlich.

Fazit: Nach den Ergebnissen dieser Interventionsstudie bewirkte eine vierwöchige fettarme Diät eine Veränderung der Fettsäure-Zusammensetzung im Serum, die signifikant das Wachstum von LNCaP-Prostatakarzinomzellen hemmte. Künftige Interventionsstudien sollten das Potenzial einer Niedrig-Fett-Diät als Option zur Prävention und Therapie des Prostatakarzinoms thematisieren, raten die Autoren.

zi

Aronson WJ et al. Growth inhibitory effect of low fat diet on prostate cancer cells: Results of a prospective, randomized dietary intervention trial in men with prostate cancer. J Urol 2010; 183: 345-50.

Das richtige Fett ist entscheidend: Omega-3Fettsäuren aus Fisch hemmen das Wachstum von Prostatakarzinomzellen, sie sollten daher in der Ernährung gegenüber Omega-6-Säuren aus Geflügel, Eiern oder auch Pflanzenölen überwiegen. 